\title{
CULTURAL INFLUENCE AND LANGUAGE ACQUISITION OF A SYRIAN IMMIGRANT GIRL IN ALABAMA
}

\author{
Shushanik Vardanyan ${ }^{1}$, James M. Ernest ${ }^{2}$, Fran Perkins ${ }^{3}$ \\ Ph.D. student Early Childhood Education \\ University of Alabama at Birmingham \\ 905 Chapel Creek Drive, Hoover, Alabama 35226-2219 \\ suzan@uab.edu1 ,jernest@uab.edu²,fperkins@bhm.k12.al.us ${ }^{3}$
}

\begin{abstract}
Using ethnography and case study approaches from qualitative methodology, this study examined a Syrian immigrant child's language acquisition and culture adaptation in the United States. Data were gathered through semi-structured interviews with the teachers and the mother of the child, participant observations during home visits, and field notes during classroom observations. The child's culture and language learning were conceptualized through the lens of Bronfenbrenner's (1994) ecological model and Funds of Knowledge approach to education (Ferreiro \& Teberosky, 1985). The article documented factors that facilitated and negatively impacted on her process of becoming bilingual and her cultural adaptation after moving to an English speaking country. Implications for fostering a better school and home relationship was discussed.
\end{abstract}

Keywords: culture adaptation, immigrants, home visits, bronfenbrenner, funds of knowledge, language acquisition

\section{INTRODUCTION}

Vast amounts of literature emphasize the benefits of home visits which provide a better strategy for meeting students' needs, particularly those who are at high risk such as immigrants, low socioeconomic status (SES), and children with diverse challenges (Dunst, Bruder, \& EspeSherwindt, 2014; Faber, 2015; Johnson \& Johnson, 2016; Kinney, 2015; Lyn \& Bates, 2010; Meyer \& Beth-Mann, 2011; Reglin, 2002). A limited ability to speak English is a shared challenge among immigrant children in the US (Garrett \& Holcomb, 2005; Glenn, 2002). With an increase in demographic diversity in the US, educators are challenged to acquire cultural knowledge while working with children from diverse nationals (Kumar, Seay, \& Karabenick, 2015). It is well documented that English Language Learners (ELLs) and immigrant children best learnt a new language when they are able to socialize with native and immigrant peers while utilizing their native and new languages simultaneously (Biesta, 2011; Glenn, 2002; Solorzano, 2008; Spring, 2008). Biesta (2011) described the notion of learning as "ongoing transactions with the environments in and through which we act" (p. 204). In this sense, learning cannot be seen immediately, hence the challenge is to find strategies for identifying learning outcomes. Also, in the process of settling into new environments, immigrant children have been known to face challenges with their language proficiency and cultural identity (Smith, 2013; Tavares, 2012); access to individual and community-level resources (GolashaBoza, 2005); and different family demographics (Colbert 2010). 
The aim of this research was to examine observations made during school and home visits with a non-English speaking Syrian immigrant child to document factors that facilitated and negatively impacted on her process of becoming bilingual and her cultural adaptation after moving to an English speaking country.

\section{Conceptual framework}

The conceptual framework of this study derived from Bronfenbrenner's Ecological Theory (Brendtro, 2006; Bronfenbrenner, 1994) and a Funds of Knowledge approach to informing the researcher (Alghamdi, Newton, Sharkins, \& Ernest, 2016; Ferreiro \& Teberosky, 1985; Moll, 2014; Moll, Amanti, Neff, \& Gonzalez, 1992; Kinney, 2015). The Funds of Knowledge approach included teachers visiting student's homes for research purposes (Moll et al., 1992) and promoting mutual relationship between home and school of a child (Alghamdi et al., 2016). The visits were neither casual, nor school-business oriented. Instead, the teacher took the role of a learner and established mutual relationship with families by exchanging information and practices between the family and the school. This type of home visits "reduce the insulator of classrooms, and contribute to the academic content and lessons" (Moll et al., 1992, p. 139). Through the Funds of Knowledge approach, teachers view students' culture, language and intellectual differences as a source of learning opportunities rather than challenges in education (Kinney, 2015). Furthermore, Moll (2014) noted the benefit of "bridging between resources in and outside the classroom" as a social connection which provides a valuable resource for teaching and learning (p. 136). As Bredtro (2006) stated, "one can only gain an accurate understanding of a child by attending to transactions within the family, school, peer group, and neighborhood" (p. 163).

When considering an ecological model of development, a child is influenced by certain environmental layers such as microsystem, exosystem, mesosystem, macrosystem and chronosystem forces (Brendtro, 2006). The first and the most significant system which has direct impact on the growing child is called a microsystem, which is the heart of this study. The microsystem is relatively more observable and easy for analysis compared to the rest of the systems in the model (Bronfenbrenner, 1994). Influential figures within a microsystem are families (parents \& siblings), the school, peers, neighborhood play areas, and anyone or anything that is in direct contact with the child. A particular importance is given to the interrelationships between people within the microsystem which are called mesosystem influences, and include home and school, peer and home, and school and peer's impacts on a child's growth. The exosystem includes broader influences related to, for example, where the child's school was, how the community supported the family, and how the parents work place and recent move from a wartorn area indirectly affected the child. The macrosystem is a "societal blueprint for a particular culture or subculture" (Bronfenbrenner, 1994, p. 40). Finally, the chronosystem was added to the model which considers how the "person-context-processtime" relationship evolves as the child and family adjust to new surroundings. (Thomas, 2005, p. 353).

\section{Literature Review}

Mutual partnership between parents and educators have the capacity to promote "an immediate positive change" in the academic life of students; including better performance on home assignments, higher scores on tests, and improved reading and writing skills (Reglin, 2002, p. 155). Dunst et al.'s research (2014) in the US found professionals engaged in home visits able to provide support and guidance for the parents. This visits strengthened family capacity and 
secured long term learning provision both for parents and children. The increase in familycentered care provided self-efficacy for parents.

Family-centered care may, however, vary from one culture to another. For example, in Africa mothers are not urged to teach their babies to sleep in a separate room, because infants typically sleep with their mothers (Nowak-Fabrikowski \& Shkandrij, 2004). Therefore, examining the cultural context of a child is important for distinguishing the structures between the child's development and his or her environment (Moll et al., 1992; Rios-Aguilar \& Kiyama, 2012). For example, when understanding the thought processes of a bilingual child, one recommendation is to analyze the cultural and social capital of the child because the acquisition of a second language starts by learning words and concepts along with the experiences lived in the new country (Nowak-Fabrikowski \& Shkandrij, 2004). As Bennett and Grant (2016) noted, "people are nested within and are an inseparable part of their community" (p. 2).

Home visits by teachers are not without challenges. Taveras (1998) surveyed teacher's perception of home visits, and found that $78 \%$ of the educators never had training. Moreover, $70 \%$ of the teachers had never conducted a home visit, and the 30 percent who conducted home visits were either from Head Start or a Daycare program (p. 8). Similarly, Kocyigit (2015) identified potential problems with regard to home visits by interviewing parents, teachers, and administers in a school in Turkey. The teachers related issues such as: 1) negative attitudes of the families, 2) lack of time, 3) financial cost for families, 4) gender (in case the teacher was a male), and 5) the objections of the teacher's spouses. Parents mentioned issues related to unannounced visits and teacher's unwillingness to visit homes. Finally, the administers indicated: 1) parents' negative attitudes because they viewed home visits as a control or exploring the negative situations, 2) transportations, and 3) teacher's unwillingness.

Regardless of the challenges, research consistently indicated that home visits allow teachers to better understand children's strengths and challenges at school through establishing rapport and trust between the parents and teachers (Dunst \& Trivette, 2009; Hynes, 2015; Johnson \& Johnson, 2016; Meyer \& Beth-Mann, 2011; Reyes, Iddings, \& Feller, 2016; Subero, Vila, \& Esteban-Guitart, 2015; Velez-Ibanes \& Greenberg, 1992).

\section{METHODS}

\section{Approach, Participants, and Site}

The researcher employed a qualitative study method using ethnography and case study approaches (Rossman \& Rallis, 2011). The participants of this study were purposefully selected (Creswell, 2012) and the main participant was a nine-year-old Syrian girl who emigrated from Syria a month prior to the data collection. Additional participants were her mother, and her English, Arabic, and ELL teachers. For the purpose of the participants' confidentiality, pseudonyms are used. The classroom observations, home visits, and face to face interviews were conducted in a large urban city in the South of the US.

\section{Data Collection}

The data were collected through semi-structured interviews with the teachers and the mother of the child, participant observations during home visits, and field notes during classroom 
observations. The interviews were audio-recorded, and later transcribed by the researcher. The duration of each interview ranged from 30 to 45 minutes.

The researcher also acknowledged the limitations of this qualitative study. One of the limitations was that "qualitative data analysis was not-off-the-shelf; rather, it was custom-built, revised, and choreographed" (Creswell, 2012, p. 150). Hence, the researcher played an influential role during data collection and analysis (Rossman \& Rallis, 2011). Therefore, the researcher acknowledged her own biases brought into the study that was beyond her epistemological or theoretical framework (Merriam \& Tisdell, 2016).

\section{Role of Researcher}

The fact that the researcher was an Armenian Christian married to a Syrian Muslim man, had both emic (i.e. insider) and etic (i.e. outsider) knowledge while conducting this study (Merriam \& Tisdell, 2016). The concept of emic and etic have derived from anthropology, where emic means looking at a phenomenon from perspectives of within the culture, as opposed to the perspectives of an outsider (i.e. etic). The researcher's emic knowledge about Muslim culture and Syrian culture allowed the researcher to produce more insightful observations, and communicate effectively with Muslim participants. At the same time, as the researcher was also of a Christian faith in the deep South of the USA, etic knowledge allowed for the researcher to position different cultural, religious, and educational norms in relation to others, thereby strengthening the authenticity of data for collection and analysis.

\section{Credibility}

The credibility of the data was assured by the use of triangulation through classroom observations, interviews, and home visits (Patton, 2015) and member checks were applied to data analysis (Merriam \& Tisdell, 2016). This helped to avoid possible misinterpretations of the information shared by the participants. Both strategies (i.e. triangulation and member checks) also helped to reduce the researcher's own biases. Furthermore, the researcher assured that the results were consistent with the data in order to secure the "dependability" or "consistency" of the information (Merriam \& Tisdell, 2016, p. 251).

\section{RESULTS}

\section{Data from the English Teacher}

The researcher asked the English teacher about parental involvement. Questions were framed in terms of any initiatives that the school took in order to involve parents in their children's learning, any activities that the school provided, and parents' responses to those initiatives. Questions also involved differentiating strategies, and children's funds of knowledge for facilitating a strong connection between child's home and school lives.

The teacher indicated the Islamic Academy's Quest for Readers and Achievers (IQRA) program that helped children to raise their fluency and interest in reading. The program started two years ago and as she stated they were in the process of improving it. Despite the fact that teachers had continuous professional development, she believed that teachers needed more practice in order to improve how they helped children with literacy development. The teacher stated that parental involvement was limited, however she was positive that they will have more 
involvement as the program continues to grow. She also mentioned that the school principal used to visit children in the class and occasionally read story to the children.

To the question of how teachers inform the parents about their school plans, she reported that "first of all, all of the announcements are made on 'Jumma' (meaning Friday) at all of the 'Masjets' (meaning Masques) of all area". Also they reached out to parents through the school website, Facebook page, notes, phone calls, and emails.

When asked about the cultural capital of the students, the teacher pointed out the importance of the Islamic community in America. She noted that the, "Muslim community is relatively small [in the city], hence we have closer ties within the community". She continued, "Yemenis know the Yemenis, Syrians know the Syrians...everybody comes together in the Mosque for the big prayer... and everybody knows somebody. It is a network... a spider web... everybody is connected in some sort of way..." Furthermore, family gathering during school events was also a way to facilitate mutual communication between the school and home.

\title{
Data from the ELL Class
}

The school provided personalized ELL classes for the child twice a week. The purpose of the ELL class observation was to identify the methods that supported the child to acquire the new language. A typical session began with the teacher asking the child to read the written sentence from the board. The child with little difficulty was able to read the sentence, "The learning objective of today's lesson is adjectives". The child's pronunciation of words (e.g. adjectives) was corrected by the teacher. Then, she asked the child to tell her the meaning of certain words. When the child was not able to tell the teacher what a word meant, the teacher translated it into Arabic and made several sentences that included adjectives in them. She used a mixture of Arabic and English languages during sessions. In a similar process, the teacher would write again on the board, (e.g., "The brilliant student is not here today"), and asked the child to find the noun, repeating the process. The ELL teacher reported that at the beginning, the child used to cry and was emotionally sensitive throughout the day at school. As she stated,

\begin{abstract}
I used to take her for a school tour and simply speak to her and show the facilities in our school. For example, the playground, the library... At the beginning, I used to speak in Arabic with her. When she was more settled I was able to take her in the class and used both Arabic and English languages and teach her English grammar. It was important for me to focus on her emotional development first. Only when she was emotionally stable I was able to teach her English.
\end{abstract}

After the ELL session, the child's next learning station was in the Arabic class. The child was followed by the investigator who sat at the end of the classroom for observing her participation in the Arabic lesson

\section{Data from the Arabic Class}

Children's desks in the Arabic class were isolated. There were three boys and four girls in the class. Although the investigator did not understand much of the conversation during the lesson, she was able to guess the idea and observe the child's level of participation in class. Children spoke almost everything in Arabic except one or two children who occasionally switched into English. The lesson began with a revision of a story. The focus child was overly enthusiastic about participating in group discussions as the teacher had to sign with her hand and ask the child to let others also have a turn. Next part of the lesson was to role-play the story. The child decided to take the role of a crow. The children were completely engaged and talkative during 
the role play, however, they were able to carry out their responsibilities independently. The last part of the lesson was to write down the correct answers as part of the reading comprehension task. The child was reluctant to write the answers down. Moreover, the teacher insisted her to write the answers in full sentences. The teacher made a remark on that and let the observer know that the child usually did not like written tasks. Later, the observer asked the child in private to understand the reasons for not liking the written work. The child reported, "It's just too easy. Why write if I know it?"

\section{Data from the Child's Mother}

The mother shared her experiences with regard to learning Arabic and English languages. Also, she shared the challenges and experiences when helped her child's home assignments. The mother recalled how her older brother used to sit with her and read Arabic stories. She said that "It helped me to love books and learn Arabic poems... I really don't remember how I learnt to write in Arabic, but I remember how I learnt English...In Syria, that time we had English classes from Grade 5. We just learn letters, words and some sentences. I didn't learn much from school". However, when she was in Grade 9, her brother encouraged her taking private classes for three months in order to learn conversational English. She remembered that "the classes were based on watching English movies without Arabic subtitles, and we should try to guess just the idea". She said that it was hard at the beginning but the same time it was fun. Through movies she learnt the English pronunciation and enhanced her listening skills. "Later, I loved watching movies at home and tried to understand the meaning without reading Arabic subtitles". Currently she speaks English quite well, and as she stated it was because of those three months' sessions and her brother's support at home. As for helping her kids for their homework, she mentioned that:

\footnotetext{
"in Syria, teachers payed too much attention to the neatness of the written work and how clean the child's copybooks and books were. For example, if a child scribbles in her copybook, the teachers will tell the child to rewrite the entire work again in a new copybook. I am happy that here in America teachers neither focus on the neatness nor have strict requirements for handwriting. But you know, on the other hand, children learn to be vigilant and responsible for taking care of their work, that's why I do not know which is better, to be strict or like American teachers".
}

Overall, she mentioned that it was very difficult for the first two months of her fourth grade daughter, as she herself had to google the new words and helped the child for her home assignments.

\section{Data from Home Visits and Conversations with the Child}

The researcher collected data from five home visits and two outdoor get-togethers with the child and her family. The investigator was able to carry out informal conversations with the child while dining with her, playing, and walking in the nature. During home visits, the investigator payed close attention to the resources and home environment in terms of the size, comfort, neighborhood noise, weather conditions, and equipment (Thomas, 2005).

Based on the observations, the child was happy at home (e.g. ran around at home with her younger sister, played with her toys, and invited the investigator to play with her). At first, the child used to sleep on the air mattress, and had no study desk and chair. She used to lay on the floor while doing her home assignments. One day she told the investigator that she wished to 
have a table at home so she could do her work better. Happily, later she had a bed, a table, a chair, and a personal computer. The Islamic community and friends of parents from their workplace were supportive by providing essential goods for them to settle in quickly in their new home.

The investigator was curious to know the reasons why the child used to cry at school. The child reported that, "I miss my friends in Syria...I miss my grandmother, too". She was asked if she had made any friends in the US. She replied, "Every time I want to talk to someone in the school, I can't. I can't speak English”. Apparently, she seemed she had overcome that challenge as she made several friends at school.

\section{DISCUSSION}

Brendtro (2006) suggested that "one can only gain an accurate understanding of a child by attending to transactions within the family, school, peer group, and neighborhood" (p. 163), and therefore, data analysis was guided by Bronfenbrenner's bio-ecological theory of child's development. Data from the English teacher indicated that the school was a close-knit community. As she stated that "Yemenis know Yemenis, Syrians know Syrians...and everybody knows somebody... it is like a spider web". Also, school announcements were made in the Mosque where parents would also be able to communicate with each other. Taking into a consideration of Bronfenbrenner's (1996) ecological theory, these would indicate the effect of the micro- and exo-systems which influenced on the child's development. The fact that the child had moved out from her country was related to the macrosystem (i.e. the war). The cultural and religious values, along with family customs such as going to the Mosque every Friday (i.e. exosystem) were obvious from the information shared by the English teacher.

Mesosytem influences between the school and families were important in this case study. For example, during the events when families get together, they would discuss their business, work, and careers. The school and the Muslim community helped the family settle in the new environment by supporting them with the school tuition fee, and home furniture, which indicated a positive relationship between the school and home of the child. With the mesosystem relationship well formed, this had an effect on the microsystem of the child. It was clear that there was a willingness of the teachers to support the child in any way they could, which ultimately has a large effect on the child's educational development.

Thomas (2005) noted that, "influences on development can also be instigated by such physical conditions of the environment as the size and furnishings of the child's dwelling, the child's diet, the surrounding noise..." (p. 352). Hence, it is worthy to mention that the environment of the classroom was set in a way that one felt to be at home. For example, there was a couch that we would normally think of as a family couch in the classroom. The windows were covered with curtains instead of blinds. The teacher also mentioned that she preferred to use natural light from outside instead of the bulbs. Indeed, the classroom was filled with sunlight that penetrated through the windows. In the corner of the classroom there was a wardrobe-like shelf where the teacher kept her files. Although the classroom was not equipped with expensive furniture, one could feel comfortable and welcomed.

In contrast, at home the child did not initially have a chair and a desk for doing her school work. The school and parent's friends acted kindly by providing the family basic needs which influenced positively on the child's schooling. The ELL teacher's approach for helping the 
child to overcome her emotional distress was also a positive strategy. The teacher used to tour her around the school and converse with her in Arabic. Even though the child and the family were unaware of these positive factors that contributed the child's smooth transition into the new culture, they helped with the child's social and emotional development.

In regards to the child's English language development, it is important to consider the support given by the family and the school. The mother of the child was also facing challenges in terms of acquisition of the English language. She had to translate words into Arabic using a digital dictionary, and later she was able to explain and support her child with homework. Similarly, the ELL teacher had to explain the English grammar in Arabic. Initially, the ELL teacher spoke with the child only in Arabic, and gradually she started to use English phrases and sentences with the child. Observations from the Arabic and ELL classes also indicated how the child's confidence was raised. During the Arabic lesson, the child participated in the discussion with more confidence and enthusiasm than it was observed in the ELL class. This is similar to Ferreiro and Teberosky's (1985) observation of how bilingual students displayed enthusiasm during reading comprehension lessons when they were able to communicate with one another in their home language (i.e. Spanish). As the class teacher reported in this study, the child was considered to be the lowest level in English reading comprehension, and the highest level in Arabic.

However, from the child's perspective all of these did not matter as much as the relationships with her peers. Thomas (2005) indicated that it is beyond just a consideration of the teacher, or the mother who influences a child's development, but "how the child perceives the activities, roles, and interpersonal relations displayed in that settings" (p. 351). Therefore, it is important to understand what those roles, activities, and interpersonal relations mean for the child in that settings. As the child mentioned, she used to cry because she had missed her friends in Syria. Tavares (2012) pointed out this as a stress that refugee and immigrant children constantly think about their close friends and family members that were left behind in insecure places. Also, she was not able to communicate in English, thus was unable to make new friends in her school. However, during the last days of observations at school, the child used a mixture of English and Arabic languages when conversing with her peers. Moll (2014) has acknowledged the "critical role of peers in language learning" (p. 108) providing an example of how a child had learnt Spanish simply by hanging out with her peers. Finally, Goodman, Watson, and Burke (1987, p. 10) have indicated the importance of people acquiring "metalinguistic knowledge" (i.e. thinking consciously about language), and based on home and classroom observations, it was clear that peers helped with the child's metalinguistic knowledge of language.

\section{Recommendations}

Analysis of the data suggests that teachers and parents can benefit from being encouraged to use more naturalistic ways to help children learn English. Parents should be advised to take their children to public places (e.g. public libraries, parks) especially during social events where children can interact with other children. Also, reading storybooks whether online or paper books is recommended for both parent's and children's language improvement. Teachers can be encouraged to communicate with children using English and children's home languages in order them to be more comfortable when expressing their thoughts. Also, teachers and parents are advised to use the "whole language" approach advocated by Goodman (2005), which opposed teaching isolated words or grammar method without any context. 


\section{CONCLUSION}

The research in this study was collected from the parents, the school, and the child. The child's literacy development was analyzed using Bronfenbrenner's bio-ecological theory of child development as a lens. There were multiple factors that influenced the child's language acquisition which would have not been discovered by "narrow approaches to assessment instruments which target the child as a problem" (Brendtro, 2006, p. 163). Macrosystem influences brought the child into the new culture (i.e. the war in Syria). The exosystem effects contributed so the child could overcome the initial culture shock, and better enabled the child with a smooth transition into the new environment. The positive mesosystem relationships also supported the child to satisfy her basic needs, and gave the family hope for the child's healthy development. Finally, the microsystem such as child-home, child-school, and child-peer relationships were the most influential and direct impact on her social and emotional development as well as her literacy acquisition.

\section{REFERENCES}

Alhghamdi, A. A., Newton, A. B., Sharkins, K. A., \& Ernest, J. M. (2016). A tale of three children: A funds-ofknowledge cross-cultural perspective with an emphasis on early literacy development. Mid-South Literacy Journal, 2(1), 2-13.

Bennett, J., \& Grant, N. S. (2016). Using an ecomap as a tool for qualitative data collection in organizations. New Horizons in Adult Education \& Human Resource Development, 28(2), 1-13.

Biesta, G. (2011). From learning cultures to educational cultures: Values and judgements in educational research and educational improvement. International Journal of Early Childhood, 43(3), 199-210. doi:10.1007/s13158-011-0042-x

Brendtro, L. K. (2006). The vision of Uri Bronfenbrenner: Adults who are crazy about kids. Reclaiming Children and Youth, 15(3), 162-166.

Bronfenbrenner, U. (1994). Ecological models of human development. In International Encyclopedia of Education, 3 ( $2^{\text {nd }}$ ed). Oxford: Elsevier.

Colbert, J. A. (2010). Welcoming newcomer children: The settlement of young immigrants and refugees: A resource for teachers and others with an interest in supporting the settlement of young children from birth through kindergarten. Canada: Fairmeadow Publication.

Creswell, J. W. (2013). Qualitative inquiry and research design: Choosing among the five

approaches $\left(3^{\mathrm{d}}\right.$ ed.). Thousand Oaks, CA: Sage.

Dunst, C. J., Bruder, M. B., \& Espe-Sherwindt, M. (2014). Family capacity-building in early childhood intervention: Do context and setting matter? School Community Journal, 24(1), 37-48.

Dunst, C. J., \& Trivette, C. M. (2009). Meta-analytic structural equation modeling of the influences of familycentered care on parent and child psychological health. International Journal of Pediatrics. doi: $10.1155 / 2009 / 576840$

Faber, N. (2015). Connecting with students and families through home visits. American Educator, 39(3), 24-27.

Ferreiro, E., \& Teberosky, A. (1985). Literacy before schooling. Portsmouth, NH: Heineman.

Garrett, J. E., \& Holcomb, S. (2005). Meeting the needs of immigrant students with limited English ability. International Education, 35(1), 49-62.

Glenn, C. L. (2002). Two-way bilingual education. Principal, 82, 28-31.

Golasha-Boza, T. (2005). Assessing the advantages of bilingualism for the children of immigrants. Center for Migration Studies of New York, 39(3), 721-753.

Goodman, K. (2005). Making sense of written language: A lifelong journey. Journal of Literacy Research, 37(1), $1-24$.

Goodman, Y. M., Watson, D. J., \& Burke, C. L. (1987). Reading Miscue Inventory: Alternative procedures. New York, Richard C. Owen Publication.

Hynes, W. (2015). Meet the family: Home visits by teachers help build relationships and create trust with students' families. Teaching Tolerance, 48, 26-30.

Johnson, E. J., \& Johnson A. B. (2016). Enhancing academic investment though home-school connections and building on ELL students' scholastic funds of knowledge. Journal of Language \& Literacy Education, 12(1), 104-121. 
Kinney, A. (2015). Compelling counternarratives to deficit discourses: An investigation into the funds of knowledge of culturally and linguistically diverse U.S. elementary students' households. Qualitative Research in Education, 4(1), 1-25. doi:10.4471/qre.2015.54

Kocyigit, S. (2015). Family involvement in preschool education: Rationale, problems and solutions for the participants. Educational Sciences: Theory \& Practice, 15(1), 141-157.

Kumar, R., Seay, N., \& Karabenick, S. A. (2015). Immigrant Arab adolescents in ethnic enclaves: Physical and phenomenological contexts of identity negotiation. Cultural Diversity and Ethnic Minority Psychology, 21(2), 201-212.

Lyn, M., \& Bates, A. B. (2010). Home visits: How do they affect teachers' beliefs about teaching and diversity? Early Childhood Education Journal, 38, 179-185.

Merriam, S. B. \& Tisdell, E. (2016). Qualitative research: A guide to design and implementation. San Francisco: Jossey-Bass Publishers.

Meyer, J. A., Mann, M. B., \& Becker, J. (2011). A five-year follow-up: Teachers' perceptions of the benefits of home visits for early elementary children. Early Childhood Education Journal, 39, 191-196.

Moll, L. C. (2014). L. S. Vygotsky and education. New York: Routledge.

Moll, L. C., Amanti, C., Neff, D., \& Gonzalez, N. (1992). Funds of knowledge for teaching: Using a qualitative approach to connect homes and classrooms. Theory into Practice, 31(2), 132-141.

Nowak-Fabrykowski, K., \& Shkandrij, M. (2004). The symbolic world of the bilingual child: Digressions on language acquisition, culture and the process of thinking. Journal of Instructional Psychology, 31(4), 284292.

Patton, M. Q. (2015). Qualitative research and evaluation methods: Integrating theory and practice $\left(4^{\text {th }}\right.$ Ed.). Saint Paul, MN: Sage.

Reglin, G. (2002). Project Reading And Writing (R.A.W.): Home visitations and the school involvement of highrisk families. Education, 123(1), 153-160.

Reyes, I., Iddings, A. C. D. S., \& Feller, N. (2016). Building relationships with diverse students and families: A funds of knowledge perspective. Journal of Early Childhood Literacy, 16(1), 8-33. doi:10.1177/1468798415584692

Rios-Aguilar, C., \& Kiyama, J. M. (2012). Funds of Knowledge: An approach to studying Latina(o) students' transition to college. Journal of Latinos and Education, 11(2),2-16. doi:10.1080/15348431.2012.631430

Rossman, G. \& Rallis, S. (2011). Learning in the Field: An Introduction to Qualitative Research. Thousand Oaks, CA: SAGE Publications.

Smith, S. (2013). Would you step through my door? Visiting low-income kids in their homes often sheds light on their hidden strengths. Educational Leadership, 70(8), 76-78.

Solorzano, R. (2008). High stake testing: Issues, implications, and remedies for English language learners. Review of Education Research, 78(2), 260-329. doi:10.3102/0034654308317845

Spring, J. (2008). Research on globalization and education. Review of Educational Research, 78(2), $330-363$. doi:10.3102/0034654308317846

Subero, D., Vila, I., \& Esteban-Guitart, M. (2015). Some contemporary forms of the Funds of Knowledge approach. Developing culturally responsive pedagogy for social justice. International Journal of Educational Psychology, 4(1), 33-53. doi:10,4471/ijep.2015.02

Taveras, G. (1998, December 7). Home visits: From the teacher's perspective. ERIC.

Thomas, R. M. (2005). Comparing theories of child development (6th ed). Belmont, CA: Wadsworth.

Velez-Ibanez, C. G., \& Greenberg, J. B. (1992). Formation and transformation of funds of knowledge among U.S.-Mexican households. Anthropology \& Education Quarterly, 23(4), 313-335. 